\title{
Association between maternal HIV infection and low birth weight and prematurity: a meta-analysis of cohort studies
}

Peng-Lei Xiao ${ }^{1,2,3}$, Yi-Biao Zhou ${ }^{1,2,3^{*}}$, Yue Chen ${ }^{4}$, Mei-Xia Yang ${ }^{5}$, Xiu-Xia Song ${ }^{1,2,3}$, Yan Shi ${ }^{1,2,3}$ and Qing-Wu Jiang ${ }^{1,2,3}$

\begin{abstract}
Background: To assess the association between maternal human immunodeficiency virus (HIV) infection and low birth weight (LBW)/prematurity (PTD), we conducted a meta-analysis of cohort studies of HIV infected and uninfected women.

Methods: Several English and Chinese databases were searched (updated to May 2015) to find the studies reporting infant outcomes associated with exposure to maternal HIV infection during pregnancy. Relevant articles were manually selected based on several inclusion and exclusion criteria.

Results: Fifty-two cohort studies including 15,538 (for LBW) and 200,896 (for PTD) HIV infected women met the inclusion criteria. There was significant heterogeneity among studies for maternal HIV infection associated with LBW/PTD $\left(I^{2}=71.7 \%, P<0.05\right.$, and $I^{2}=51.8 \%, P<0.05$ for LBW and PTD, respectively). The meta-analysis demonstrated that the maternal HIV infection was significantly associated with both LBW (pooled odds ratio (OR): 1.73, $95 \%$ confidence interval (Cl): 1.64, 1.82, $P<0.001$ ) and PTD (pooled OR: 1.56, 95 \% Cl: 1.49, 1.63, $P<0.001$ ). No significant difference in the relationship between maternal HIV infection and adverse pregnancy outcomes was detected among the groups of different study periods. HIV infected women were at slightly higher risk of LBW in developing countries compared with women in developed countries (OR: 2.12 (95 \% Cl: 1.81, 2.48) vs. 1.75 (95 \% Cl: $1.44,2.12)$ ). Antiretroviral drugs usage did not significantly change the associations of maternal HIV exposure with LBW and PTD.

Conclusions: HIV infected women were at higher risk of having a low birth weight infant or a preterm delivery infant compared with uninfected women. Such associations did not change significantly over time or were not significantly affected by the usage of antiretroviral drugs.
\end{abstract}

Keywords: Maternal HIV infection, Meta-analysis, Low birth weight, Preterm delivery

\section{Background}

Although new infections of human immunodeficiency virus (HIV) show a descending trend in recent years, the number of people living with HIV has been rising year by year. More than 16 million (95\% CI: 14.8 million, 17.4 million) female adults had been infected with HIV

\footnotetext{
* Correspondence: ybzhou@fudan.edu.cn

${ }^{1}$ Fudan University School of Public Health, Building 8, 130 Dong'an Road, Xuhui District, Shanghai 200032, China

${ }^{2}$ Key Laboratory of Public Health Safety, Fudan University, Ministry of Education, Building 8, 130 Dong'an Road, Xuhui District, Shanghai 200032 China

Full list of author information is available at the end of the article
}

by the end of 2012 [1]. There is a risk for mother-tochild transmission of HIV. Among HIV infected women who took the highly active antiretroviral therapy (HAART), studies reported that the mother-to-child transmission (MTCT) rate ranged from 1 to $5 \%$ [2], and it was around $10 \%$ among women who did not $[3,4]$. There is also a possibility that maternal HIV infection has severe impacts on pregnancy outcomes. It has been reported that HIV infected women are more likely to encounter adverse pregnancy outcomes, such as low birth weight (LBW) and preterm delivery (PTD) [5]. And it is suggested that LBW 
and PTD are important risk factors for post-neonatal mortality and morbidity and other adverse events including neurodevelopmental problems [6,7].

Studies have provided inconsistent results for the association between maternal HIV infection and LBW/PTD. Some studies suggested that maternal HIV infection could increase the risk of LBW and PTD [8-10], but others reported no significant association between them [11-13]. Brocklehurst et al. [5] summarized the study results published between 1983 and 1996. They found the association of maternal HIV infection with adverse pregnancy outcomes such as LBW and PTD, but failed to assess the effect of antiretroviral drugs on it. There have been many new studies on the association between maternal HIV infection and adverse pregnancy outcomes reported in the past 20 years. For this reason, we conducted a meta-analysis to provide an update on the relationship between maternal HIV infection and LBW/PTD. In addition, there has been a rapid progress of medication and heath care for HIV infected women, and we assessed the influence of such a progress on the relationship.

\section{Methods}

\section{Search strategy}

We searched English databases (EMBASE, MEDLINE via PubMed and Web of Science) and Chinese databases (China National Knowledge Infrastructure, Wan Fang database, Sino Med and VIP) up to May 31, 2015 for studies reporting infant outcomes among women exposed and unexposed to HIV infection during pregnancy. Articles were searched using the following search terms: "maternal HIV infection" "HIV infected mothers/HIV infected pregnant women" combined with "pregnant outcomes/birth outcomes" "low birth weight (LBW)" "prematurity/preterm birth/preterm delivery (PTD)". Only cohort studies were included.

\section{Study selection}

The relevant articles were manually selected based on the following criteria: (1) Types of studies: Prospective or retrospective cohort studies; unsystematic observations (case series or case reports) were excluded from all analyses. Because cohort studies demonstrate strong intensity compared with other observational studies in terms of causality. (2) Types of participants: Women with HIV infection during pregnancy. (3) Types of comparators: Women with no HIV infection during pregnancy. (4) Types of pregnancy outcomes: LBW (defined as birth weight $<2500 \mathrm{~g}$ ) and PTD (defined as gestational age $<37$ weeks). (5) All the articles reported or allowed the calculation of odd ratios (OR) with corresponding $95 \%$ confidence intervals (95\% CIs). In order to standardize the results, all measures of effect were expressed as OR and 95 \% CIs. (6) Published in English or Chinese, and full text was available. When the same cohort population was used in several papers, only the most recent ones were included in the current analysis, i.e., the same study data were only used once in the study.

\section{Assessment of study quality and data extraction}

We adapted the Newcastle-Ottawa Scale suggested by Zeng et al. [14] to measure study quality. Scores were awarded for each criterion met, and the maximum score was 9. Studies were graded high quality if the score was no less than 7 and low quality if the score was under 7 . Abstracts and conference papers were graded 0 for quality and were included in the low quality category for sensitivity analyses.

Two researchers selected literature in accordance with the inclusion and exclusion criteria, and extracted data after independent verification. The following information was extracted from each study: subject of the literature, the author, year of publication,location of the study population, number of women in the two groups, odds ratio and its $95 \%$ CIs for LBW and PTD associated with maternal HIV infection, exposure to maternal use of antiretroviral drugs before or during pregnancy.

\section{Statistical analysis}

Stata12.0 software was used to analyze the data. For both LBW and PTD, if no significant heterogeneity for their associations with maternal HIV exposure among the studies included was found $\left(P>0.1, I^{2}<50 \%\right)$, a fixed effect model was used to calculate ORs and their $95 \%$ CIs. Otherwise,a random effects model was used. The sensitivity of data was analyzed by using the method which reduced the biggest weight of literature. Funnel plot and the Egger's linear regression method were used to assess publication bias.

No ethics statement to declare.

\section{Results}

Articles included in the Meta-analysis and study select process

A total of 1148 articles were identified. After removing duplicate publications and based on our inclusion and exclusion criteria, 52 articles were included in our analysis (Table 1, Fig. 1) and of them, 43 were related to LBW and 40 were related to PTD. They were all published in English. More than $60 \%$ of the articles were conducted in Africa $(n=24)$ and America $(n=11)$, and 8 were from Europe $(n=2)$ and Asia $(n=6)$.

The prevalence of infants born before 37 weeks' gestation ranged from 5.2 to $73.0 \%$ in HIV infected women and 2.2 to $32 \%$ in HIV uninfected women. The prevalence of LBW among HIV infected women ranged from 3.4 to $56.0 \%$ and 2.5 to $36.9 \%$ in HIV uninfected women. Odds ratios for the association of HIV exposure 
Table 1 Characteristics of the included studies

\begin{tabular}{|c|c|c|c|c|c|c|c|c|c|c|c|c|}
\hline \multirow[t]{2}{*}{ First author, publication year } & \multirow[t]{2}{*}{ Study year } & \multirow[t]{2}{*}{ Design type } & \multirow{2}{*}{$\begin{array}{l}\text { Study } \\
\text { location }\end{array}$} & \multicolumn{3}{|l|}{ Low birth weight } & \multicolumn{3}{|l|}{ Preterm delivery } & \multirow[t]{2}{*}{$\mathrm{Q}^{\mathrm{a}}$} & \multirow[t]{2}{*}{ Confounding } & \multirow{2}{*}{$\begin{array}{l}\text { Exposure } \\
\text { to ARVs }\end{array}$} \\
\hline & & & & $\begin{array}{l}\text { Number of } \\
\text { infected women }\end{array}$ & Rate & OR & $\begin{array}{l}\text { Number of } \\
\text { infected women }\end{array}$ & Rate & $\mathrm{OR}$ & & & \\
\hline Hira et al., 1989 [30] & 1987 & Prospective & Zambia & 227 & 9.7 & 3.75 & 227 & 6.6 & 1.37 & 5 & No & No \\
\hline Lallemant et al., 1989 [31] & 1987-1988 & Prospective & Congo & 64 & 26.0 & 3.22 & & & & 3 & No & No \\
\hline Selwyn et al., 1989 [32] & 1989 & Prospective & USA & & & & 25 & 32.0 & 1.01 & 0 & No & No \\
\hline Braddick et al., 1990 [33] & 1986-1989 & Retrospective & Malawi & 167 & 9.0 & 3.00 & 165 & 16.0 & 1.50 & 7 & No & No \\
\hline Semprini et al., 1990 [34] & 1985- & Prospective & Italy & & & & 74 & 15.0 & 0.42 & 5 & No & No \\
\hline Halsey et al., 1990 [35] & 1976-1985 & Prospective & Haiti & 199 & 18.6 & 1.78 & 199 & 6.9 & 3.35 & 0 & No & No \\
\hline Lepage et al., 1991 [36] & 1988-1989 & Prospective & Rwanda & 218 & 17.2 & 1.40 & & & & 9 & No & No \\
\hline Mayers et al., 1991 [37] & 1985-1989 & Prospective & USA & & & & 33 & 36.0 & 1.76 & 6 & No & No \\
\hline Alger et al., 1993 [38] & 1987-1991 & Prospective & USA & 101 & 27.7 & 1.05 & & & & 0 & No & No \\
\hline St Louis et al., 1993 [39] & 1989-1990 & Prospective & Congo & & & & 324 & 20.4 & 1.31 & 0 & No & Not \\
\hline Bulterys et al., 1994 [40] & 1989-1992 & Prospective & Rwanda & 274 & 7.8 & 1.79 & 297 & 28.0 & 1.50 & 9 & No & No \\
\hline Temmerman et al., 1994 [8] & 1989-1991 & Prospective & Kenya & 285 & 19.6 & 1.40 & 315 & 24.1 & 1.90 & 9 & No & No \\
\hline Taha et al., 1995 [41] & before 1995 & Prospective & Malawi & 663 & 20.1 & 2.55 & & & & 7 & No & Not stated \\
\hline Kumar et al., 1995 [42] & 1992-1993 & Prospective & India & 150 & 21.6 & 2.12 & 150 & 22.0 & 3.29 & 9 & No & Not stated \\
\hline Mauri et al., 1995 [43] & 1986-1992 & Prospective & Italy & & & & 38 & 16.0 & 1.91 & 7 & No & Not stated \\
\hline Bloland et al., 1995 [44] & 1987-1990 & Prospective & Malawi & 92 & 17.4 & 1.76 & 85 & 6.5 & 1.51 & 9 & No & No \\
\hline Markson et al., 1996 [45] & 1989-1990 & Prospective & USA & 772 & 29.0 & 2.04 & & & & 7 & Yes & Not stated \\
\hline Bucceri et al., 1997 [11] & 1985-1993 & Prospective & Italy & 153 & 32.0 & 1.20 & 151 & 21.0 & 0.90 & 3 & No & Not stated \\
\hline Castetbon et al., 1999 [46] & 1992-1993 & Prospective & Rwanda & 177 & 18.6 & 2.24 & 177 & 21.5 & 2.03 & 9 & $\begin{array}{l}\text { Yes, LBW: aOR }=1.21 \\
(0.58-2.56)\end{array}$ & Not stated \\
\hline Coley et al., 2001 [12] & 1995-1997 & Prospective & Tanzania & 433 & 15.2 & 1.25 & 420 & 27.1 & 1.11 & 7 & $\begin{array}{l}\text { Yes, aOR }=1.21 \text { and } \\
1.11 \text { for LBW and PTD }\end{array}$ & Not stated \\
\hline Ellis et al., 2002 [9] & 1988-1995 & Retrospective & USA & 524 & 29.4 & 2.11 & 524 & 28.9 & 1.83 & 7 & $\begin{array}{l}\text { Yes, aOR:LBW:1.45 } \\
(1.14-1.86) \text { PTD:1.32 } \\
(1.04-1.70)\end{array}$ & Not stated \\
\hline Ticconi et al., 2003 [47] & 2000-2001 & Prospective & Zimbabwe & 82 & & 4.36 & 82 & 53.7 & 3.33 & 7 & $\begin{array}{l}\text { Yes, LBW: aOR = } 3.16 \\
(1.80-5.54) ; \text { PTD: } \\
\text { aOR=4.10(2.17-7.75) }\end{array}$ & Not stated \\
\hline Friis et al., 2004 [48] & 1996-1997 & Retrospective & Zimbabwe & 360 & 14.7 & 1.74 & 360 & 21.1 & 1.46 & 9 & Not mentioned & Not stated \\
\hline van Eijk et al., 2004 [49] & $1996-2000$ & Retrospective & Kenya & 641 & 4.8 & 1.81 & 641 & 8.1 & 1.16 & 6 & No & Not stated \\
\hline Boer et al., 2007 [50] & 1997-2003 & Retrospective & Holland & 142 & 17.0 & 1.72 & 143 & 18.0 & 2.24 & 4 & Yes & Yes \\
\hline Schulte et al., 2007 [10] & 1989-2004 [10] & Retrospective & USA & 1744 & 26.0 & 1.45 & 1614 & 27.0 & 1.77 & 9 & $\begin{array}{l}\text { Yes, } a O R=1.34 \text { for } L B W \\
\text { and } a O R=1.65 \text { for } P T D\end{array}$ & Yes \\
\hline
\end{tabular}


Table 1 Characteristics of the included studies (Continued)

\begin{tabular}{|c|c|c|c|c|c|c|c|c|c|c|c|c|}
\hline Haeri et al., 2008 [51] & before 2008 & Retrospective & USA & 151 & 30.0 & 3.04 & 151 & 18.0 & 1.63 & 0 & $\begin{array}{l}\text { Yes (spontaneous PTD } \\
\mathrm{aOR}=2.27(1.2-4.3))\end{array}$ & Yes \\
\hline Mitgitti et al., 2008 [52] & 1997-2002 & Retrospective & Thailand & 266 & 12.0 & 1.78 & 247 & 8.5 & 1.23 & 7 & $\begin{array}{l}\text { Yes, LBW aOR = } 1.98 \\
(1.26-3.10)\end{array}$ & Not stated \\
\hline Habib et al., 2008 [53] & 1999-2006 & Retrospective & Tanzania & & & & 434 & 10.4 & 1.25 & 5 & Yes & Yes, partly \\
\hline Ezeaka et al., 2009 [54] & $2002-2005$ & Prospective & Nigeria & 220 & 16.8 & 3.47 & & & & 7 & No & Not stated \\
\hline Uneke et al., 2009 [55] & 2006 & Prospective & Nigeria & 3 & 25.0 & 3.16 & & & & 0 & No & Not stated \\
\hline Musana et al., 2009 [56] & 2004-2005 & Prospective & Kenya & 68 & 56.0 & 2.80 & 68 & 73 & 2.20 & 3 & No & Not stated \\
\hline Olagbuji et al., 2010 [57] & $2007-2008$ & Prospective & Nigeria & 203 & 18.2 & 5.43 & 203 & 12.8 & 1.98 & 9 & No & Yes \\
\hline Pattinson et al., 2010 [58] & $2006-2008$ & Retrospective & South Africa & 3014 & 19.8 & 1.47 & & & & 0 & No & Yes, partly \\
\hline Patil et al., 2011 [13] & $2002-2003$ & Prospective & India & 212 & 31.1 & 0.77 & 212 & 13.7 & 1.13 & 7 & No & Yes, partly \\
\hline Asavapiriyanont et al., 2011 [59] & $2004-2008$ & Prospective & USA & 420 & 12.6 & 0.94 & & & & 0 & Not mentioned & Yes, partly \\
\hline Ndirangu et al., 2012 [60] & $2001-2004$ & Prospective & South Africa & 1189 & 9.8 & 1.48 & 1189 & 21.8 & 1.39 & 9 & $\begin{array}{l}\text { Yes, aOR for } \\
\text { PTD }=1.07\end{array}$ & No \\
\hline Lopez et al., 2012 [61] & 1986-2010 & Retrospective & Spain & & & & 519 & 19.7 & 2.60 & 9 & $\begin{array}{l}\text { Yes, aOR }=2.5 \\
(1.9-3.5)\end{array}$ & Yes, partly \\
\hline Chen et al., 2012 [62] & 2009-2011 & Retrospective & Botswana & & & & 9504 & 23.7 & 1.50 & 4 & $\begin{array}{l}\text { Yes, aOR = } 1.3 \\
(1.3-1.4)\end{array}$ & Yes \\
\hline Nkhoma et al., 2012 [63] & $2005-2006$ & Prospective & Malawi & 45 & 26.7 & 2.32 & & & & 4 & $\begin{array}{l}\text { Yes, aOR }=3.08 \\
(1.40-6.79)\end{array}$ & Yes \\
\hline Muhangi et al., 2013 [29] & $2003-2005$ & Prospective & Uganda & 121 & 10.0 & 1.80 & & & & 3 & No & Yes, only 5 \\
\hline Ezechi et al., 2013 [64] & 2004-2011 & Prospective & Nigeria & 2158 & 9.4 & 3.01 & 2105 & 13.1 & 2.10 & 9 & $\begin{array}{l}\text { Yes, aOR }=2.95 \\
(1.95-3.10) ; 2.05 \\
(1.3-3.1)\end{array}$ & Yes \\
\hline Duan et al., 2014 [65] & 2010-2013 & Retrospective & China & 300 & 14.7 & 6.27 & 300 & 10.3 & 1.81 & 3 & No & Yes \\
\hline He et al., 2013 [66] & $2007-2009$ & Retrospective & China & 58 & 3.4 & 0.65 & 58 & 5.2 & 1.53 & 7 & & Yes \\
\hline Wang et al., 2009 [67] & $2007-2008$ & Retrospective & China & 35 & 14.3 & 3.55 & & & & 3 & No & Yes \\
\hline Han et al., 2004 [68] & 1997-1999 & Case control & Tanzania & 37 & 18.9 & 4.43 & 37 & 16.2 & 3.68 & 3 & No & Not stated \\
\hline Dong et al., 2001 [69] & 1995-1999 & Case control & Tanzania & 86 & 16.3 & 2.40 & 86 & 14.0 & 3.08 & 3 & No & Not stated \\
\hline Macdonald et al., 2015 [70] & 2002-2003, 2010-2011 & Retrospective & Canada & 615 & 12.5 & 1.90 & 615 & 14.6 & 1.76 & 7 & Yes & Yes \\
\hline Salihu et al., 2013 [71] & 1998-2007 & Prospective & USA & 4634 & & 1.73 & 4634 & & 1.35 & 9 & Yes & Not stated \\
\hline Boyajian et al., 2012 [72] & 2003-2010 & Retrospective & Canada & 91 & 20.2 & 2.91 & 91 & 15.6 & 1.70 & 7 & Yes & Yes \\
\hline Brown et al., 2012 [73] & $2000-2008$ & Retrospective & USA & 71 & 43.7 & 4.23 & 71 & 40.9 & 2.83 & 6 & No & Yes \\
\hline Da Costa et al., 2013 [74] & 1995-2005 & Prospective & Brazil & & & & 713 & 15.0 & 1.57 & 6 & $\begin{array}{l}\text { Yes, aOR } 1.26 \\
(0.90-1.770\end{array}$ & Not stated \\
\hline
\end{tabular}

CI confidence interval, $L B W$ low birth weight; $O R$ odds ratio, aOR adjusted odds ratio, $P T D$ preterm delivery

"quality score of articles calculated by Newcastle-Ottawa Scale; ARVs" antiretroviral drugs exposure before or during pregnancy 


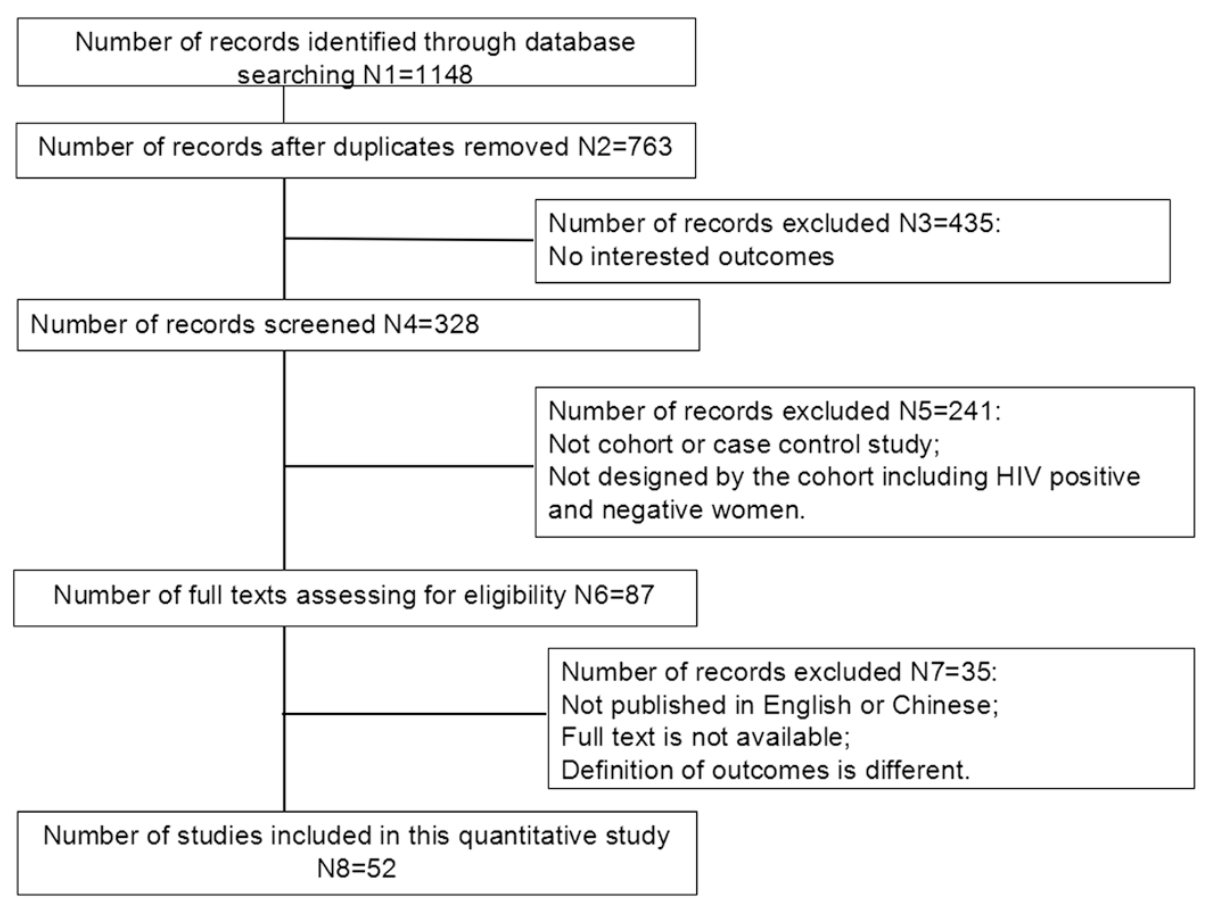

Fig. 1 Flow chart of study selection process

ranged from 0.65 to 6.27 with $\mathrm{LBW}$ and ranged from 0.42 to 3.68 with PTD.

\section{Impact of maternal HIV infection on LBW and PTD}

There was significant heterogeneity among studies for maternal HIV infection associated with LBW/PTD $\left(\mathrm{I}^{2}=\right.$ $71.7 \%, P<0.05$, and $\mathrm{I}^{2}=51.8 \%, P<0.05$ for LBW and PTD, respectively) suggesting that the summary measures need to be interpreted with caution. Pooled ORs for LBW and PTD from random effect models were presented in Figs. 2 and 3, respectively. The summary OR was 1.73 (95 \% CI: 1.64, 1.82, $P<0.001$ ) for LBW and 1.56 (95 \% CI: 1.49, 1.63) for PTD, indicating that HIV infected women had approximately 2-fold risk to deliver low birth weight or preterm babies compared with uninfected ones.

\section{Test for publication bias}

Begg's and Egger's Tests suggested that there were significant publication biases among the 43 studies of LBW (Begg's Test: $\mathrm{z}=2.15, P=0.03$; Egger's Test: $t=3.53$, $P=0.001$ ) (Additional file 1 ). After adjusted by using the Trim and Filling method, the pooled OR was 1.77 (95\% CI: 1.57, 2.00), which was near to the original OR (1.73, 95 \% CI: 1.64, 1.82). No significant publication bias was detected for the 40 articles of PTD (Begg's Test: $\mathrm{z}=0.79, \mathrm{P}=0.43$; Egger's Test: $\mathrm{t}=1.69, P=0.10$ ) (Additional file 2).

\section{Sensitivity analysis}

After removing the article that counted the biggest weight, there was no significant change of the results. The pooled ORs were 1.98 (95\% CI: 1.76, 2.23) for LBW and 1.62 (95 \% CI: 1.49, 1.77) for PTD, respectively. After stratified by location of study population, the significant associations between maternal HIV infection and LBW or PTD were still found in the studies from Africa, America and Asia, except those from Europe. Studies from Africa $(\mathrm{OR}=2.18,95 \% \mathrm{CI}$ : 1.84, 2.59), America $(\mathrm{OR}=1.80,95 \% \mathrm{CI}: 1.49,2.19)$ and Asia (OR = 1.99, 95 \%CI: 1.05, 3.74) showed significant pooled ORs for LBW, and for PTD the corresponding pooled ORs were 1.56 (95 \% CI: 1.40, 1.75), 1.69 (95\% CI: 1.53, 1.88) and 1.60 (95 \% CI: 1.10, 2.35), respectively. These associations were all significant in the two groups of developing and developed countries. No significant difference in the relationship was detected across study periods and their pooled ORs were all statistically significant for both LBW and PTD. But studies during 2005-2015 were at slightly higher risk for both LBW and PTD compared with the other two groups (Table 2).

We also conducted a subgroup analysis based on the information of antiretroviral drugs (ARVs) usage. ARVs usage before or during pregnancy did not decrease the risks of both LBW and PTD. Women who took ARVs were at similar risk of delivering low birth weight infants $(\mathrm{OR}=2.04,95 \% \mathrm{CI}: 1.61,2.57)$ compared with those did not $(\mathrm{OR}=1.75,95 \% \mathrm{CI}: 1.42,2.17)$. For PTD, the pooled 


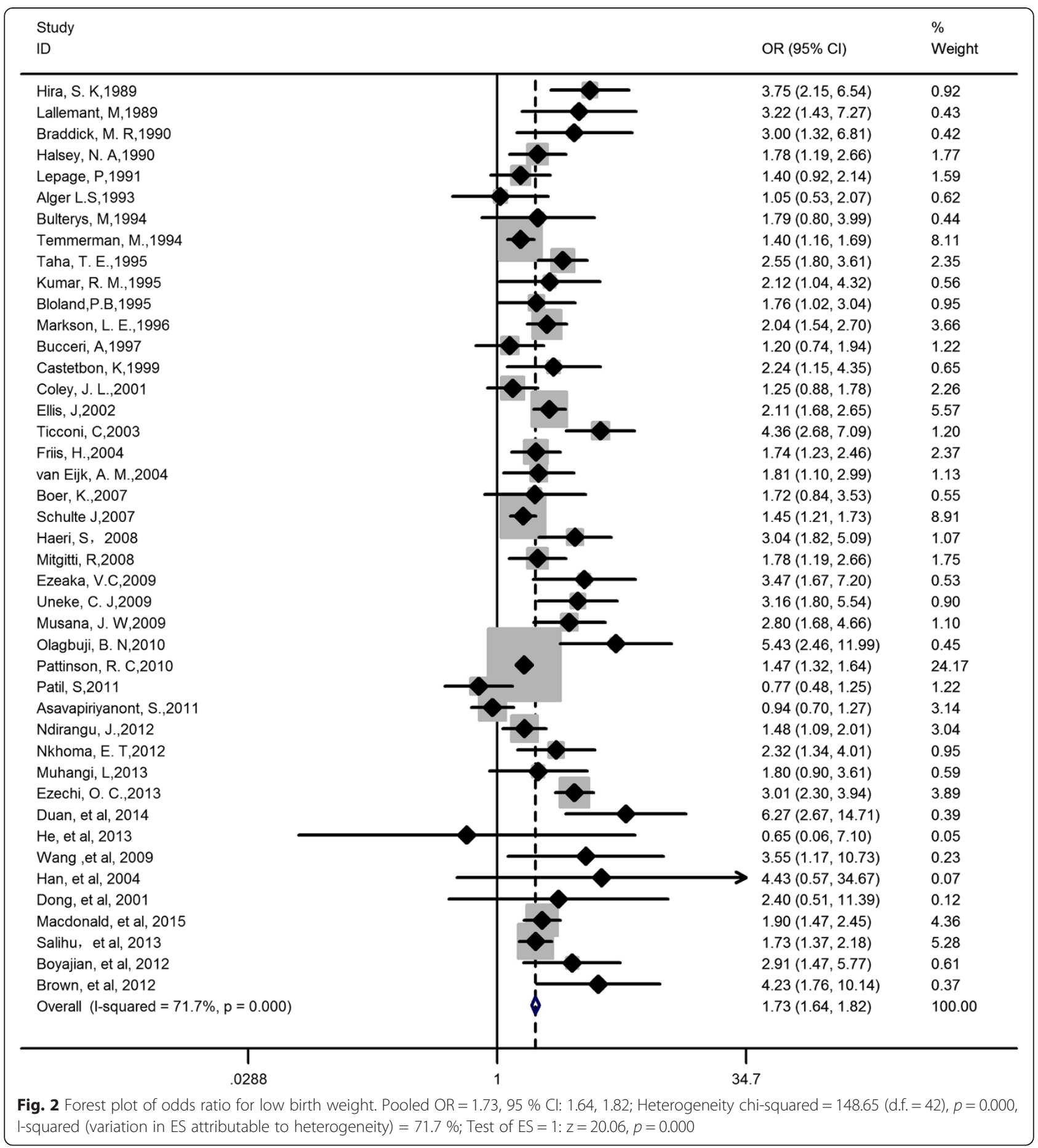

ORs were 1.77 (95 CI: 1.55, 2.02) for women who took drugs, 1.54 (95 \% CI: 1.23, 1.92) for those who did not took drug and 1.55 (95 \% CI: 1.32, 1.82) for those who provided no information about AVRs usage (Table 2).

\section{Discussion}

It has been previously reported that compared with unexposed children, children who encountered intrauterine
HIV exposure are more vulnerable to stunting, underweight and wasting, and their birth weight, height and head circumference are generally lower than their unexposed counterparts [15]. However, it was controversial for the effect of maternal HIV infection on both LBW and PTD. Brocklehurst et al. [5] reported that the increasing risks of LBW and PTD were associated with maternal HIV infection. And they found that women in 


\begin{tabular}{|c|c|c|}
\hline $\begin{array}{l}\text { Study } \\
\text { ID }\end{array}$ & OR $(95 \% \mathrm{Cl})$ & $\begin{array}{l}\% \\
\text { Weight }\end{array}$ \\
\hline Hira, S. K,1989 & $1.37(0.74,2.55)$ & 0.50 \\
\hline Selwyn, P. A,1989 & $1.01(0.31,3.31)$ & 0.14 \\
\hline Braddick, M. R,1990 & $1.50(0.88,2.55)$ & 0.69 \\
\hline SEMPRINI, A. E & $0.42(0.16,1.12)$ & 0.20 \\
\hline Halsey, N. A,1990 & $3.35(1.71,6.56)$ & 0.43 \\
\hline Mayers,M.M,1991 & $1.76(0.64,4.85)$ & 0.19 \\
\hline St, L. M,1993 & $1.31(0.88,1.96)$ & 1.21 \\
\hline Bulterys, M,1994 & $1.50(1.01,2.22)$ & 1.25 \\
\hline Temmerman, M.,1994 & $1.90(1.29,2.80)$ & 1.30 \\
\hline Kumar, R. M.,1995 & $3.29(1.52,7.12)$ & 0.33 \\
\hline Mauri, A & $1.91(0.56,6.49)$ & 0.13 \\
\hline Bloland,P.B,1995 & $1.51(0.67,3.41)$ & 0.29 \\
\hline Bucceri, A,1997 & $0.90(0.52,1.56)$ & 0.64 \\
\hline Castetbon, K,1999 & $2.03(1.11,3.71)$ & 0.53 \\
\hline Coley, J. L.,2001 & $1.11(0.87,1.42)$ & 3.24 \\
\hline Ellis, J,2002 & $1.83(1.43,2.34)$ & 3.17 \\
\hline Ticconi, C,2003 & $3.33(2.08,5.33)$ & 0.88 \\
\hline Friis, H.,2004 & $1.46(1.12,1.91)$ & 2.73 \\
\hline van Eijk, A. M.,2004 & $1.16(0.81,1.67)$ & 1.48 \\
\hline Boer, K.,2007 & $2.24(1.12,4.47)$ & 0.41 \\
\hline Schulte J,2007 & $1.77(1.48,2.11)$ & 6.18 \\
\hline Haeri, S, 2008 & $1.63(0.92,2.89)$ & 0.59 \\
\hline Mitgitti, R,2008 & $1.23(0.76,2.00)$ & 0.83 \\
\hline Habib, N. A,2008 & $1.25(0.89,1.75)$ & 1.70 \\
\hline Musana, J. W,2009 & $2.20(1.44,3.36)$ & 1.08 \\
\hline Olagbuji, B. N,2010 & $1.98(1.00,3.92)$ & 0.42 \\
\hline Patil, S,2011 & $1.13(0.55,2.30)$ & 0.38 \\
\hline Ndirangu, J.,2012 & $1.39(1.19,1.62)$ & 8.24 \\
\hline Lopez, M, 2012 & $2.60(1.92,3.53)$ & 2.08 \\
\hline Chen, J. Y.,2012 & $1.50(1.40,1.60)$ & 43.61 \\
\hline Ezechi, O. C.,2013 & $2.10(1.69,2.61)$ & 4.12 \\
\hline Duan, et al, 2014 & $1.81(0.94,3.48)$ & 0.46 \\
\hline $\mathrm{He}$, et al, 2013 & $1.53(0.15,16.12)$ & 0.04 \\
\hline Han, et al, 2004 & $3.68(0.45,29.96)$ & 0.04 \\
\hline Dong, et al, 2001 & $3.08(0.45,21.09)$ & 0.05 \\
\hline Macdonald, et al, 2015 & $1.76(1.38,2.24)$ & 3.31 \\
\hline Salihu, et al, 2013 & $1.35(1.06,1.71)$ & 3.40 \\
\hline Boyajian, et al, 2012 & $1.70(0.79,3.66)$ & 0.33 \\
\hline Brown, et al, 2012 & $2.83(1.22,6.55)$ & 0.28 \\
\hline $\mathrm{Da}$, et al, 2013 & $1.57(1.22,2.02)$ & 3.11 \\
\hline Overall $(\mathrm{I}$-squared $=51.8 \%, p=0.000)$ & $1.56(1.49,1.63)$ & 100.00 \\
\hline & & \\
\hline 1 & \\
\hline .0334 & \multicolumn{2}{|c|}{30} \\
\hline
\end{tabular}

developing countries had higher risks of both LBW and PTD than those in developed countries. Our study, which included a number of newer studies in the metaanalysis also indicated that maternal HIV infection increased the risks of both LBW and PTD. We found that these associations were not affected by different study periods or antiretroviral drugs usage. In addition, we did not find marked difference in these associations between developing and developed countries.
The HIV associated LBW and PTD might be related to the damaged human immune system, especially the reduced CD4+ T cells and immunosuppression. Previous studies documented that women with CD4 cell counts $<350$ cells $/ \mathrm{mm}^{3}$ had an increased risk of having LBW infants $(\mathrm{RR}=1.57 ; 95 \% \mathrm{CI}: 1.16,2.12)$ compared to women with higher CD4 cell counts $[16,17]$. There is a possibility that women are immunocompromised during pregnancy [18], and if accompanied with HIV infection, 
Table 2 Results of subgroup analysis

\begin{tabular}{|c|c|c|c|c|c|c|c|c|c|}
\hline \multirow[t]{2}{*}{ Factors } & \multirow[t]{2}{*}{ Groups } & \multicolumn{4}{|c|}{ Low birth weight } & \multicolumn{4}{|c|}{ Preterm delivery } \\
\hline & & No. of studies & OR $(95 \% \mathrm{Cl})$ & $P$ & $P^{2}(\%)$ & No. of studies & OR $(95 \% \mathrm{Cl})$ & $P$ & $P^{2}$ \\
\hline \multirow[t]{2}{*}{ Design type } & Prospective & 27 & $1.93(1.64,2.28)$ & $<0.001$ & 75.8 & 23 & $1.60(1.39,1.84)$ & $<0.001$ & 59.8 \\
\hline & Retrospective & 16 & $2.05(1.72,2.45)$ & $<0.001$ & 62.2 & 17 & $1.67(1.49,1.86)$ & $<0.001$ & 39.5 \\
\hline \multirow[t]{3}{*}{ Study period } & Before 1995 & 15 & $1.90(1.61,2.25)$ & $<0.001$ & 54.4 & 15 & $1.59(1.31,1.93)$ & $<0.001$ & 41.2 \\
\hline & 1995-2004 & 14 & $1.72(1.42,2.08)$ & $<0.001$ & 63.1 & 15 & $1.55(1.34,1.80)$ & $<0.001$ & 66.1 \\
\hline & 2005-2015 & 14 & $2.52(1.90,3.33)$ & $<0.001$ & 83.7 & 10 & $1.79(1.55,2.06)$ & $<0.001$ & 37.9 \\
\hline \multirow[t]{4}{*}{ Study location } & Africa & 24 & $2.18(1.84,2.59)$ & $<0.001$ & 73.5 & 19 & $1.56(1.40,1.75)$ & $<0.001$ & 52.6 \\
\hline & America & 11 & $1.80(1.49,2.19)$ & $<0.001$ & 73.1 & 11 & $1.69(1.53,1.88)$ & $<0.001$ & 6.2 \\
\hline & Europe & 2 & $1.34(0.90,2.00)^{\mathrm{a}}$ & 0.15 & 0 & 5 & $1.40(0.73,2.68)^{a}$ & 0.32 & 80.4 \\
\hline & Asia & 6 & $1.99(1.05,3.74)$ & 0.03 & 77.3 & 5 & $1.60(1.10,2.35)$ & 0.02 & 27.3 \\
\hline \multirow[t]{2}{*}{ Country economic } & Developing & 31 & $2.12(1.81,2.48)$ & $<0.001$ & 72.5 & 26 & $1.60(1.44,1.76)$ & $<0.001$ & 48.9 \\
\hline & Developed & 12 & $1.75(1.44,2.12)$ & $<0.001$ & 71.9 & 14 & $1.67(1.41,1.98)$ & $<0.001$ & 52.5 \\
\hline \multirow[t]{3}{*}{ ARVs exposure } & No & 10 & $1.75(1.42,2.17)$ & $<0.001$ & 51.7 & 9 & $1.54(1.23,1.92)$ & $<0.001$ & 44.5 \\
\hline & Not stated & 17 & $2.07(1.78,2.42)$ & $<0.001$ & 51.2 & 17 & $1.55(1.32,1.82)$ & $<0.001$ & 56.2 \\
\hline & Yes & 16 & $2.04(1.61,2.57)$ & $<0.001$ & 82.1 & 14 & $1.77(1.55,2.02)$ & $<0.001$ & 52.4 \\
\hline Overall & & 43 & $1.98(1.76,2.23)$ & $<0.001$ & 71.7 & 40 & $1.62(1.49,1.77)$ & $<0.001$ & 51.8 \\
\hline
\end{tabular}

No number, $\mathrm{Cl}$ confidence interval, $A R V s$ antiretroviral drugs, $O R$ odds ratio

${ }^{\mathrm{a}}$ No significant difference/no statistical significance $(P>0.05)$

disease progress might be accelerated. Simultaneously, reproductive tract infections, which are contributed to the incidence of adverse pregnancy outcomes, would occur more frequently due to the immunosuppression [19]. Some studies have reported that HIV-1 can replicate in the placenta [20], and it has also been shown that HIV-1 infection may alter the cytokine profile in the placenta [21, 22]. This may affect the function of placenta during pregnancy, and then restrict the development of fetal, which might be another incentive of LBW and PTD.

After stratified by antiretroviral drugs use before or during pregnancy, we found that HAART or other regimens of antiretroviral therapy (ART) had no obvious effect on the associations between maternal HIV infection and LBW/PTD. It is suggested that intrauterine ARVs exposure did not decrease or increase the risk of LBW or PTD in HIV infected women. And this is consistent with the findings reported by van der Merwe et al. and Townsend et al. [3, 4]. However, Papp et al. [23] suggested that Protease Inhibitor (PI)-based ART could increase the risk of adverse pregnancy outcomes mainly due to lower level of progesterone, which was significantly associated with fetal weight. Sibude et al. [24] also found that ARVs and, particularly, with the initiation of ritonavir-boosted PI therapy during pregnancy were correlated with PTD in HIV infected women. Though we did not found such effect of ARVs on the association between maternal HIV infection and LBW/PTD, no details of information for AVRs and therapy regimens may contribute to this. We found that studies during 2005-2015 were at slightly higher risk for both LBW and PTD compared with the other two groups, it might be related with the increasing use of combination ART earlier in pregnancy, and more use of PI for ART in recent years. Kourtis et al. [25] had found that use of PI in ART may increase the risk of PTD compared with ART without PI. And different initiation time of ART have different influences on the risk of PTD. Townsend et al. [26] also indicated that HARRT was associated with PTD. We have ever tried to analyze the data by the information of ART regimens, initiation time, ARVs duration, etc., however, there were not enough information to support the analysis of the data after stratification, for the information of ART were not provided or not detailed described in all articles. Thus we could not know if there any influences of different ART regimens or different initiation time on the association between maternal HIV infection and LBW/PTD. On the other hand, ARVs might be responsible for adverse pregnancy outcomes such as LBW and PTD, but its high effectiveness in the prevention for mother to child transmission outweighed its risk of LBW/PTD suggested by Santini et al. [27].

Maternal HIV infection was found to be related with both LBW and PTD in some places such as Africa and America. Moreover, no difference in the relationship was detected among the different study periods. This, to a certain degree, reflected the non-ideal treatment and health care development in reducing the risk of LBW and PTD for HIV infected women. So we look forward to finding new regimens or methods combined with other measurements like perinatal health care for pregnant women to decrease the risk of adverse pregnancy outcomes. 
There are several limitations to note. Our metaanalysis dataset was not complete due to some restrictions of accessing to full texts. Another limitation is that we could not determine if maternal HIV infection had direct effects on LBW/PTD. We could not rule out the possibility that the association is secondary to HIVassociated deficiency, for example maternal nutrition deficiency, or other risk factors of adverse pregnancy, such as drug use, smoking, etc. And we could not get the association between maternal HIV infection and LBW/ PTD after controlling for different clinical stages of HIV infection in this analysis because of the absence of such information. The relationship between maternal HIV infection and LBW/PTD is likely affected by the clinical stage of HIV infection. Study conducted by Coley et al. in Tanzania [28] indicated that although HIV infected asymptomatic women did not have a higher risk of having LBW infants compared with uninfected women (OR = 1.25; 95 \% CI: 0.88, 1.79), symptomatic HIV-infected women who were in Stage 2 or higher according to the WHO staging system had about 2-time higher risks for low birth weight $(\mathrm{RR}=2.29$; $95 \% \mathrm{CI}: 1.34,3.92)$ and prematurity ( $R R=1.93$; $95 \% \mathrm{CI}: 1.35,2.77)$ compared with HIV-uninfected ones. This is consistent with the finding of Bucceri et al. [11] and Muhangi et al. [29]. Publication bias is always a concern for systematic reviews. Publication bias in this meta-analysis was analyzed by using funnel plot and the Begg's and Egger's test methods. Significant publication bias was detected among studies of LBW and proper adjustment was conducted. And we found the results of this analysis had good stability by sensitivity analysis.

\section{Conclusions}

In conclusion, the findings of this study indicated that maternal HIV infection was associated with increased risks of both low birth weight and preterm delivery. However, the associations were moderate. No difference in the relationships between maternal HIV infection and adverse pregnancy outcomes was detected among different study periods. ARVs were not found to decrease risks of either low birth weight or preterm delivery associated with maternal HIV exposure.

\section{Additional files}

Additional file 1: Funnel plot of publication bias for low birth weight. (TIFF 124 kb)

Additional file 2: Funnel plot of publication bias for preterm delivery. (TIFF $127 \mathrm{~kb}$ )

\section{Abbreviations}

HIV: Human immunodeficiency virus; LBW: Low birth weight; PTD: Preterm delivery; HAART: Highly active antiretroviral therapy; MTCT: Mother-to-child transmission; ARVs: Antiretroviral drugs; PI: Protease inhibitor.

\section{Competing interests}

The authors declare that they have no competing interests.

\section{Authors' contributions}

P-LX participated in the data collection, statistical analysis and interpretation of the meta-analysis data and the preparation of the manuscript. Y-BZ, YC and Q-WJ participated in the interpretation of the data and in the critical review and revision of the manuscript draft. X-XS, M-XY and YS performed data collection for the study and participated in the preparation of the manuscript. All authors read and approved the final manuscript.

\section{Acknowledgements}

The authors would like to acknowledge Bao-Dong Yao for his guide of this study.

\section{Author details}

'Fudan University School of Public Health, Building 8, 130 Dong'an Road, Xuhui District, Shanghai 200032, China. ${ }^{2}$ Key Laboratory of Public Health Safety, Fudan University, Ministry of Education, Building 8, 130 Dong'an Road, Xuhui District, Shanghai 200032, China. ${ }^{3}$ Fudan University Center for Tropical Disease Research, Building 8, 130 Dong'an Road, Xuhui District, Shanghai 200032, China. ${ }^{4}$ School of Epidemiology, Public Health and Preventive Medicine, Faculty of Medicine, University of Ottawa, 451 Smyth Road, Ottawa, ON K1H 8 M5, Canada. ${ }^{5}$ Xuhui Center for Disease Prevention and Control, 50 Yongchuan Road, Xuhui District, Shanghai 200032, China.

Received: 14 June 2015 Accepted: 4 October 2015

Published online: 08 October 2015

\section{References}

1. UNAIDS. UNAIDS World AIDS Report. Geneva, Switzerland. 2014:A130-A135.

2. Townsend CL. Low rates of mother-to-child transmission of HIV following effective pregnancy interventions in the United Kingdom and Ireland, 2000-2006. AIDS. 2008;22(8):973-81

3. van der Merwe K, Hoffman R, Black V. Birth outcomes in South African women receiving highly active antiretroviral therapy: a retrospective observational study. J Int AIDS Soc. 2011, 14(42). doi:10.1186/1758-2652-14-42.

4. Townsend CL, Cortina-Borja M, Peckham CS, Tookey PA. Antiretroviral therapy and premature delivery in diagnosed HIV-infected women in the United Kingdom and Ireland. AIDS. 2007;1019-1026.

5. Brocklehurst $P$, French $R$. The association between maternal HIV infection and perinatal outcome: a systematic review of the literature and metaanalysis. BJOG. 1998;105(8):836-48.

6. Le Doare K, Bland R, Newell ML. Neurodevelopment in children born to HIVinfected mothers by infection and treatment status. Pediatrics. 2012;130(5):e1326-44.

7. McCormick MC. The contribution of low birth weight to infant mortality and childhood morbidity. N Engl J Med. 1985;312(2):82-90.

8. Temmerman M, Chomba EN, Ndinya-Achola J. Maternal human immunodeficiency virus-1 infection and pregnancy outcome. Obstet Gynecol. 1994;83(4):495-501.

9. Ellis J, Williams H, Graves W, Lindsay MK. Human immunodeficiency virus infection is a risk factor for adverse perinatal outcome. Am J Obstet Gynecol. 2002;186(5):903-6.

10. Schulte J, Dominguez K, Sukalac T, Bohannon B, Fowler MG. Declines in low birth weight and preterm birth among infants who were born to HIV-infected women during an era of increased use of maternal antiretroviral drugs: Pediatric Spectrum of HIV Disease, 1989-2004. Pediatrics. 2007;119(4):e900-6.

11. Bucceri A, Luchini L, Rancilio L. Pregnancy outcome among HIV positive and negative intravenous drug users. Eur J Obstet Gynecol Reprod Biol. 1997;72(2):169-74.

12. Awoleke JO. Maternal risk factors for low birth weight babies in Lagos, Nigeria. Arch Gynecol Obstet. 2012;285(1):p1-6.

13. Patil S, Bhosale R, Sambarey P. Impact of maternal human immunodeficiency virus infection on pregnancy and birth outcomes in Pune India. AIDS Care. 2011;23(12):1562-9.

14. Zeng X, Liu H, Chen X, Leng W. Series four of Meta-analysis: quality assessment tools for observational study. Chin J Evid Based Cardiovasc Med. 2012;312(04):297-9.

15. McGrath CJ, Nduati R, Richardson BA. The Prevalence of Stunting Is High in HIV-1-Exposed Uninfected Infants in Kenya. J Nutr. 2012;142(4):757-63. 
16. van der Merwe K, Hoffman R, Black V. Birth outcomes in South African women receiving highly active antiretroviral therapy: a retrospective observational study. AIDS Soc: J Int; 2011. p. 14(42).

17. Kim HY, Kasonde P, Mwiya M. Pregnancy loss and role of infant HIV status on perinatal mortality among HIV-infected women. BMC Pediatr. 2012;12:138.

18. Dong J, Ma D, Ma Y, Liu X. Effects of human immunodeficiency virus infection on pregnancy outcome. Chin J Obst Gyneco. 2001;36(8):462-4.

19. Tanton C, Weiss HA, Le Goff J. Correlates of HIV-1 genital shedding in Tanzanian women. PLoS ONE. 2011;6(3):e17480.

20. Kumar SB, Handelman SK, Voronkin I. Different regions of HIV-1 subtype C env are associated with placental localization and in utero mother-to-child transmission. J Virol. 2011;85(14):7142-52.

21. Moussa M, Roques P, Fievet N. Placental cytokine and chemokine production in HIV-1-infected women: trophoblast cells show a different pattern compared to cells from HIV-negative women. Clun Exp Immunol. 2001;125(3):455-64.

22. Faye A, Pornprasert S, Mary JY. Characterization of the main placental cytokine profiles from HIV-1-infected pregnant women treated with antiretroviral drugs in France. Clun Exp Immunol. 2007;149(3):430-9.

23. Papp E, Mohammadi H, Loutfy MR. HIV protease inhibitor use during pregnancy is associated with decreased progesterone levels, suggesting a potential mechanism contributing to fetal growth restriction. J Infect Dis. 2015:211(1):10-8.

24. Sibiude J, Warszawski J, Tubiana R. Premature delivery in HIV-infected women starting protease inhibitor therapy during pregnancy: role of the ritonavir boost? Clin Infect Dis. 2012;54(9):1348-60.

25. Kourtis AP, Schmid CH, Jamieson DJ. Use of antiretroviral therapy in pregnant HIV-infected women and the risk of premature delivery: a metaanalysis. AIDS. 2007;21(5):607-15.

26. Townsend C, Schulte J, Thorne C. Antiretroviral therapy and preterm delivery-a pooled analysis of data from the United States and Europe. BJOG. 2010;117(11):1399-410.

27. Santini-Oliveira M, Friedman RK, Veloso VG. Incidence of antiretroviral adverse drug reactions in pregnant women in two referral centers for HIV prevention of mother-to-child-transmission care and research in Rio de Janeiro Brazil. Braz J Infect Dis. 2014;18(4):372-8.

28. Coley JL, Msamanga Gl, Fawzi M. The association between maternal HIV-1 infection and pregnancy outcomes in Dar es Salaam Tanzania. BJOG. 2001;108(11):1125-33.

29. Muhangi L, Lule SA, Mpairwe H. Maternal HIV infection and other factors associated with growth outcomes of HIV-uninfected infants in Entebbe Uganda. Public Health Nutr. 2013;16(9):1548-57.

30. Hira SK, Kamanga J, Bhat GJ. Perinatal transmission of HIV-I in Zambia. BMJ. 1989;299(6710):1250-2.

31. Lallemant M, Lallemant-Le-Coeur S, Cheynier D. Mother-child transmission of HIV-1 and infant survival in Brazzaville Congo. AIDS. 1989;3(10):643-6.

32. Selwyn PA, Schoenbaum EE, Davenny K. Prospective study of human immunodeficiency virus infection and pregnancy outcomes in intravenous drug users. JAMA. 1989;261(9):1289-94.

33. Braddick MR, Kreiss JK, Embree JB. Impact of maternal HIV infection on obstetrical and early neonatal outcome. AIDS. 1990;4(10):1001-5.

34. Semprini AE, Ravizza M, Bucceri A, Vucetich A, Pardi G. Perinatal outcome in HIV-infected pregnant-wome. Gynecol Obstet Inves. 1990;30(1):15-8.

35. Halsey NA, Boulos R, Holt E. Transmission of HIV-1 infections from mothers to infants in Haiti. Impact on childhood mortality and malnutrition. JAMA. 1990;264(16):2088-92.

36. Lepage $P$, Dabis F, Hitimana DG. Perinatal transmission of HIV-1: lack of impact of maternal HIV infection on characteristics of livebirths and on neonatal mortality in Kigali Rwanda. AIDS. 1991;5(3):295-300.

37. Mayers MM, Davenny K, Schoenbaum EE. A prospective study of infants of human immunodeficiency virus seropositive and seronegative women with a history of intravenous drug use or of intravenous drug-using sex partners, in the Bronx New York City. Pediatrics. 1991;88(6):1248-56.

38. Alger LS, Farley JJ, Robinson BA. Ineractions of hunman-immunodeficiencyvirus infection and pregnancy. Obstet Gynecol. 1993;82(5):787-96.

39. St LM, Kamenga M, Brown C. Risk for perinatal HIV-1 transmission according to maternal immunologic, virologic, and placental factors. JAMA. 1993:2853-2859.

40. Bulterys M, Chao A, Munyemana S. Maternal human immunodeficiency virus 1 infection and intrauterine growth: a prospective cohort study in Butare Rwanda. Pediatr Infect Dis J. 1994;13(2):94-100.
41. Taha TE, Dallabetta GA, Canner JK. The effect of human immunodeficiency virus infection on birthweight, and infant and child mortality in urban Malawi. Int J Epidemiol. 1995;1022-1029.

42. Kumar RM, Uduman SA, Khurranna AK. Impact of maternal HIV-1 infection on perinatal outcome. Int J Gynaecol Obstet. 1995;49(2):137-43.

43. Mauri A, Piccione E, Deiana P, Volpe A. Obstetric and perinatal outcome in human immunodeficiency virus-infected pregnant women with and without opiate addiction. Eur J Obstet Gynecol Reprod Biol. 1995;58(2):135-40.

44. Bloland PB, Wirima JJ, Steketee RW. Maternal HIV infection and infant mortality in Malawi: evidence for increased mortality due to placental malaria infection. AIDS. 1995;721-726.

45. Markson LE, Turner BJ, Houchens R. Association of maternal HIV infection with low birth weight. J Acquir Immune Defic Syndr Hum Retrovirol. 1996;227-234

46. Castetbon K, Ladner J, Leroy V. Low birthweight in infants born to African HIV-infected women: relationship with maternal body weight during pregnancy: Pregnancy and HIV Study Group (EGE). J Trop Pediatr. 1999:45(3):152-7.

47. Ticconi C, Mapfumo M, Dorrucci M. Effect of maternal HIV and malaria infection on pregnancy and perinatal outcome in Zimbabwe. J Acquir Immune Defic Syndr. 2003;34(3):289-94.

48. Friis $\mathrm{H}$, Gomo E, Nyazema N. Maternal body composition, HIV infection and other predictors of gestation length and birth size in Zimbabwe. Br J Nutr. 2004;92(5):833-40.

49. van Eijk AM, De Cock KM, Ayisi JG. Pregnancy interval and delivery outcome among HIV-seropositive and HIV-seronegative women in Kisumu Kenya. Trop Med Int Halth. 2004;9(1):15-24.

50. Boer K, Nellen JF, Patel D. The AmRo study: pregnancy outcome in HIV-1infected women under effective highly active antiretroviral therapy and a policy of vaginal delivery. BJOG. 2007;114(2):148-55.

51. Haeri S, Shauer M, Dale M. Obsteric and newborn outcomes in HIV infected women receving highly active antiretroviral therapy (HAART). Am J Obstet Gynecol. 2008;199(6):S123.

52. Mitgitti R, Seanchaisuriya P, Schelp FP, Marui E, Yanai H. Low birth weight infants born to HIV-seropositive mothers and HIV-seronegative mothers in Chiang Rai, Thailand. Southeast Asian J Trop Med Public Health. 2008:39(2):273-8.

53. Habib NA, Daltveit AK, Bergsjo P. Maternal HIV status and pregnancy outcomes in northeastern Tanzania: a registry-based study. BJOG. 2008;115(5):616-24.

54. Ezeaka VC, Iroha EO, Akinsulie AO, Temiye EO, Adetifa IM. Anthropometric indices of infants born to HIV-1-infected mothers: a prospective cohort study in Lagos, Nigeria. Int J STD AIDS. 2009;545-548.

55. Uneke CJ, Duhlinska DD, Ujam TN. Effects of Maternal Plasmodium falciparum Malaria and HIV infection on Birth Weight in Southeastern Nigeria. Mcgill J Med. 2009;12(2):42.

56. Musana JW, Ojwang SBO, Khisa W, Kiarie JN. Pregnancy outcomes in mothers with advanced human immunodeficiency virus disease. East Afr Med J. 2009:86(10):480-5.

57. Olagbuji BN, Ezeanochie MC, Ande AB, Oboro VO. Obstetric and perinatal outcome in HIV positive women receiving HAART in urban Nigeria. Arch Gynacol Obstet. 2010;281(6):991-4.

58. Pattinson RC, Hulsbergen MH, Van Hoorick $L$. The effect of maternal HIV infection on maternal conditions and perinatal deaths in southwest Tshwane. Facts Views Vis Obgyn. 2010;2(4):227-31.

59. Asavapiriyanont S, Kasiwat S. Prevalence of low birthweight infants in HIV-infected women delivered in Rajavithi Hospital. J Med Assoc Thai. 2011;94 Suppl 2:S66-70.

60. Ndirangu J, Newell ML, Bland RM, Thorne C. Maternal HIV infection associated with small-for-gestational age infants but not preterm births: evidence from rural South Africa. Hum Reprod. 2012;27(6):1846-56.

61. Lopez M, Figueras F, Hernandez S. Association of HIV infection with spontaneous and iatrogenic preterm delivery: effect of HAART. AIDS 2012:26(1):37-43

62. Chen JY, Ribaudo HJ, Souda S. Highly active antiretroviral therapy and adverse birth outcomes among HIV-infected women in Botswana. J Infect Dis. 2012;206(11):1695-705

63. Nkhoma ET, Kalilani-Phiri L, Mwapasa V, Rogerson SJ, Meshnick SR. Effect of HIV infection and Plasmodium falciparum parasitemia on pregnancy outcomes in Malawi. Am J Trop Med Hyg. 2012;29-34.

64. Ezechi OC, Gab-Okafor CV, Oladele DA. Pregnancy, obstetric and neonatal outcomes in HIV positive Nigerian women. Afr J Reprod Health. 2013;17(3):160-8. 
65. Duan RF. A Pilot Study on Feeding and Malnutrition Status of Infants Born to HIV-positive Mothers in High HIV Prevalence Areas of Yunnan Province. Kunmimg Medical University (Yunnan Province, China) 2014:p73.

66. He LL, Tang ZW. Analysis of pregnancy outcomes for $58 \mathrm{HIV}$ infected women. J Youjiang Med Univ Natio. 2013;35(03):317.

67. Wang SF. Analysis of 50 cases for HIV posotive pregnant women. Xinjiang Med J. 2009;39(04):34-5.

68. Han YJ. Tracking of pregnancy outcomes of HIV infected women in Tanzania. Chin J Misdiagnostics. 2004;4(08):1240-1.

69. Dong JC, Ma YQ, Ma YY. Effects of human immunodeficiency virus infection on pregnancy outcome. Chin J Obstet Gynecol. 2001;36(08):13-5.

70. Macdonald EM, Ng R, Bayoumi AM. Adverse neonatal outcomes among women living with HIV: a population-based study. J Obstet Gynaecol Can. 2015;37(4):302-9.

71. Salihu HM, Mogos MF, August EM. HIV infection and its impact on fetal outcomes among women of advanced maternal age: a propensity score weighted matching approach. AIDS Res Hum Retroviruses. 2013;29(3):581-7.

72. Boyajian T, Shah PS, Murphy KE. Risk of preeclampsia in HIV-positive pregnant women receiving HAART: a matched cohort study. J Obstet Gynaecol Can. 2012;34(2):136-41.

73. Brown K, Holland B, Mosquera C, Calilap C, Bardeguez A. Human immunodeficiency virus infection in advanced maternal age gravidas. AIDS Res Hum Retroviruses. 2012;28(3):265-9.

74. Da CT, Leal MC, Mota JC. Comparison of pregnancy characteristics and outcomes between HIV-infected and HIV-non-infected women in Brazil. AIDS Care. 2013;25(6):686-90.

\section{Submit your next manuscript to BioMed Central and take full advantage of:}

- Convenient online submission

- Thorough peer review

- No space constraints or color figure charges

- Immediate publication on acceptance

- Inclusion in PubMed, CAS, Scopus and Google Scholar

- Research which is freely available for redistribution 